Cameron, J.L., Capuzzi, D.M., Zuidema, G.D. \& Margolis, S. (1973) Acute pancreatitis with hyperlipemia: The incidence of lipid abnormalities in acute pancreatitis. Annals of Surgery, 177, 483.

Davidoff, F., Tishler, S. \& Rosoff, C. (1973) Marked hyperlipidemia and pancreatitis associated with oral contraceptive therapy. New England Journal of Medicine, 289, 552.

Farrell, P., Fitzgerald, P., Fitzgerald, O., McGeeney, K., Geoghegan, C. \& Hefrernan, A. (1972) Shock in acute pancreatitis and hypovolaemia. Gut, 13, 844.

GABRYELEWICZ, A. (1971) Disturbances of blood clotting and fibrinolysis in acute pancreatitis. Acta haematologica polonica, 2, 319.

Glueck, C.J., Scheel, D., Fishback, J. \& Steiner, P. (1972) Estrogen-induced pancreatitis in patients with previously covert familial type V hyperlipoproteinemia. Metabolism, 21, 657 .
GreipP, P.R., Brown, J.A. \& Gralnick, H.R. (1972) De-々 fibrination in acute pancreatitis. Annals of Internal Medi- $\mathbb{D}$ cine, 76, 73.

Pollock, A.V. (1959) Acute pancreatitis. Analysis of 100 patients. British Medical Journal, 1, 6.

Ransom, J.H.C., Roses, D.F. \& FINK, S.D. (1973) Early respiratory insufficiency in acute pancreatitis. Annals of Surgery, 178, 75.

StaCkhouse, K.L., Glass, D.D. \& Zimmerman, B. (1966) Relationships of lipoprotein lipase and hyperlipemia in pancreatitis. Surgical Forum, 17, 343.

Trapnell, J.E. (1968) Pancreatitis-acute and chronic. $\overrightarrow{0}$ British Journal of Hospital Medicine, 1, 181.

Wang, C., Strauss, L. \& Addlesburg, D. (1958) Experi- $\vec{\omega}$ mental pancreatitis and plasma lipids. Gastroenterology. 35,465 .

\title{
Testicular tumour presenting as haematemesis
}

\author{
M. R. LOCK \\ M.B.B.S., F.R.C.S.
}

Professorial Surgical Unit, Westminster Hospital, London S.W.1

\section{Summary}

The case is presented of a malignant testicular tumour which presented with a haematemesis due to multiple tumour deposits in both stomach and jejunum. No similar case has been previously recorded. The pathology and aetiology of testicular tumours are discussed.

\section{Case history}

A well developed, hirsute lorry driver aged 29 years was admitted to Westminster Hospital on 8th February 1972 with a history of dizziness and palpitations for one week. Immediately before admission he had had a small haematemesis and noted darkening of his stools. There was a history of bilateral maldescent of the testes which had been treated at the age of eleven by injections.

On examination he was clinically anaemic, there was a fist-sized mass in the right scrotum which was non-tender and indistinguishable from the right testis itself. The left scrotum was empty and the testis was not palpable.

\section{Investigations}

Haemoglobin $3.9 \mathrm{~g} \%$; E.S.R. $51 \mathrm{~mm} / \mathrm{hr}$ (Westergren); a chest $\mathrm{X}$-ray showed multiple tumour deposits in both lungs.

* Present address: St. Mark's Hospital, City Road, London, E.C.1.

\section{Progress}

He was transfused with 6 units of blood. A barium meal and follow-through, and a gastroscopy were both normal, no focus of gastro-intestinal bleeding being identified. Two bone marrow biopsies were performed and they showed normoblastic erythropoiesis with a myeloid erythroid ratio of $2: 1$ which was suggestive of haemorrhage as the cause of the anaemia. Malignant cells were not present. He continued to bleed, including a massive melaena stool. Two further barium meal and follow-through examinations failed to show any lesion. Further transfusion raised his haemoglobin to $10.6 \mathrm{~g} \%$, when laparotomy was performed.

\section{First operation 21.2.72}

Blood was found throughout the lumen of the small and large intestines from the duodeno-jejunal $\frac{D}{O}$ flexure distally. The absence of gastric and duodenal lesions was confirmed by pylorotomy. A nodule was o palpated along the anti-mesenteric border of the $N$ lumen of the proximal jejunum; on enterotomy this was found to be a smooth, soft, haemorrhagic lump $\omega$ $1 \mathrm{~cm}$ in diameter, bleeding copiously from its mucosal surface. Approximately $10 \mathrm{~cm}$ of the proximal jejunum was resected to include the lesion. $\mathbb{D}$ The liver and para-aortic nodes were free of meta-? static deposits. The right spermatic cord was divided 
at the deep inguinal ring and the testis removed. Postoperative recovery was initially good.

\section{Histological examination}

The testicular tumour was a combined teratoma and seminoma. The teratoid tissue contained well differentiated tumour together with anaplastic areas; foci of chorion carcinoma were also present. The right cord was free of tumour. The jejunal lesion was a metastasis of chorion carcinoma.

\section{Second operation 27.2.72}

Two days postoperatively severe gastro-intestinal bleeding recurred and a second operation became necessary. Another nodule was found in the jejunum distal to the site of the first resection and a further resection was carried out. Gastrotomy showed multiple punctate haemorrhages in the antral mucosa. A retrocolic Polya partial gastrectomy was performed. Following this operation the patient deteriorated rapidly and died 5 days later.

\section{Histological examination}

There were metastatic deposits of chorion carcinoma in both stomach and jejunum.

\section{Post-mortem examination}

Metastatic deposits of chorion carcinoma were found in the lungs, liver, brain and kidneys (Figs 1 and 2). Four further deposits were found in the

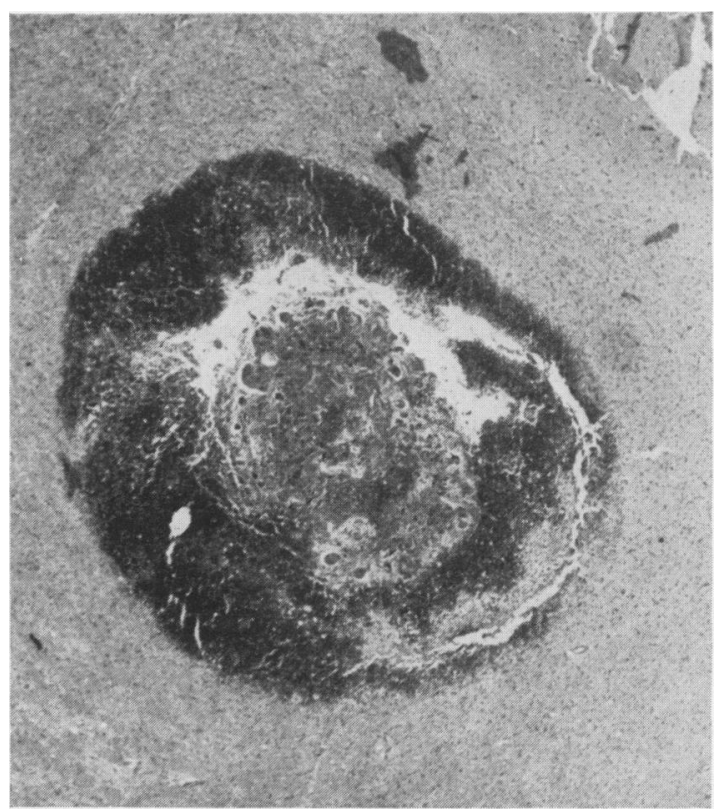

FIG. 1. Localized haemorrhagic cerebral metastasis.

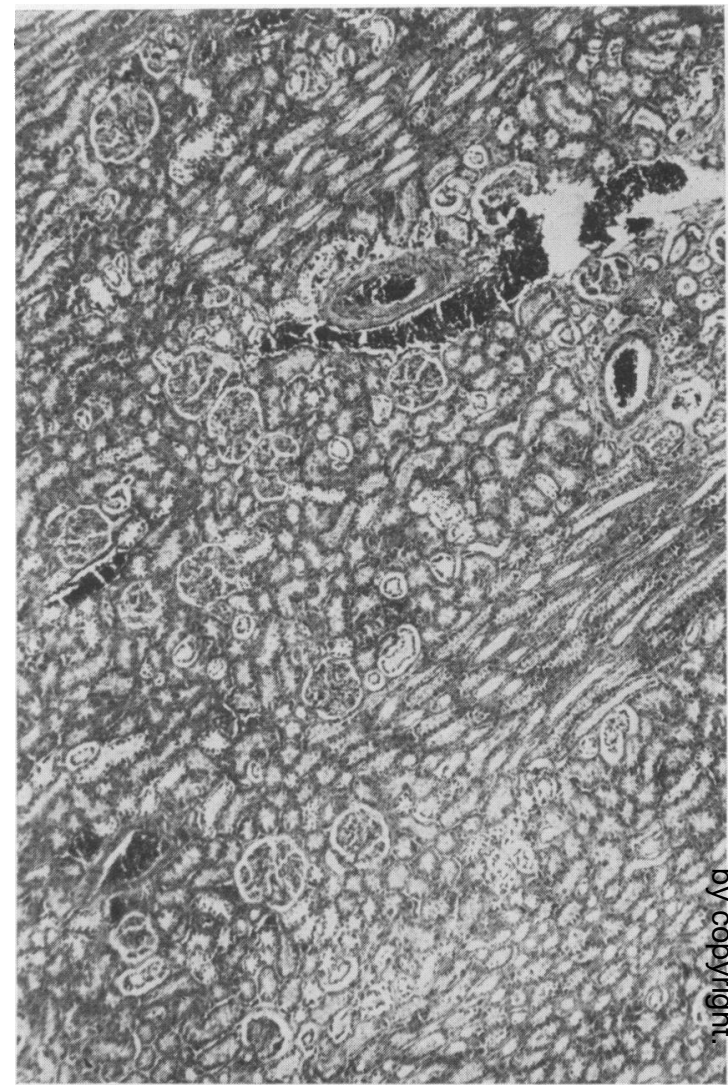

FIG. 2. Haemorrhagic deposit in the kidney.

upper jejunum but the gastric remnant was clear All the deposits consisted largely of haemorrhage with clumps and cords of malignant cells around the periphery. There was no evidence of metastases from the better differentiated parts of the primary tumour. There was no gynaecomastia.

\section{Discussion}

Gastro-intestinal haemorrhage due to metastases in both stomach and jejunum at the same time, is a most unusual feature.

In a series of nine million routine medical examinations for the United States Army, Campbell (1942) recorded an incidence of maldescent of the testis of $0.23 \%$. Stephen (1958), reviewed one hundred cases of testicular malignancy and found that $4 \%$ of $N$ tumours occurred in a maldescended testicle. Half the cases had previously undergone orchidopexy and the tumour presented in the scrotum; in the remainder the tumour was found at the external ring. Two per cent of the tumours occurred in the testis on the contralateral side ot the maldescent. Whittle (1958) has quoted a similar incidence of malignant 
change of $7 \%$. Thus in maldescent with supervening malignant change the opposite testis may just as frequently be the seat of the primary lesion as its absent colleague. This raises the possibility of the malignant change being due to environmental and particularly hormonal abnormalities. The advisability of laparotomy to search for an absent testicle may also be questioned in this light. It may later be the contralateral 'normal' testicle which becomes malignant.

Testicular tumours, especially chorion carcinoma, frequently present with the effects of their metastases. The primary lesion may be of minute size and undetected clinically but haematogenous spread produces widespread haemorrhagic metastases. These occur most frequently in lungs, lymph nodes, liver, bones and the mediastinum. Prossor (1964) found that in a series of 358 cases, $20 \%$ had metastases when first seen. The lymph nodes most frequently involved were the para-aortic group, followed by the iliac, supraclavicular and inguinal nodes. Amongst 205 cases reviewed for the Testicular Tumour Panel (Pugh, 1966) there were ninety-six cases of combined tumour, $48 \%$ of which developed metastases. In four of these the metastases were intestinal. Johnson and Strauss (1952) found one testicular tumour in eight cases of intussusception due to tumour metastases. The heart (Fleming and Harrison, 1965), endocrine glands (Rivadeneyra, 1972), suboccipital nodes (Duomi, 1962), and even the palatal tonsil have been recorded as the site of metastases from testicular tumours.

Ballanger (1963) recorded the case of a patient presenting with a history suggestive of gastric ulcer. Laparotomy revealed a solitary gastric metastasis of testicular origin, gastrectomy was followed by survival for twelve years. Salika (1966) reported the case of a chorion carcinoma presenting with gastrointestinal haemorrhage. The left testicle was clinically absent and on laparotomy multiple hepatic deposits were found and a large mass in the stomach. A gastrectomy was performed but the mass proved to be ectopic pancreatic tissue without mucosal ulceration. Post-mortem examination revealed a haemorrhagic mass along the left side of the abdominal aorta, which was the presumed site of the primary tumour in an undescended testis.
The present case is unique, with multiple deposits in both stomach and jejunum. It is probable that the initial haemorrhage was from a jejunal lesion since gastroscopy was normal in the first instance. The three negative barium investigations can only be explained by the small size of the jejunal deposits. The rapid development of the multiple gastric deposits was attributed to the debilitating trauma of the surgery and the handling of the tumour. On this occasion the primary tumour was obvious on clinical examination but the possibility of gastro-intestinal haemorrhage being due to such a rare cause should not be overlooked, the scrotum should be palpated in all cases.

\section{Acknowledgments}

To Dr R. I. S. Bayliss and Professor H. Ellis for permission to present a patient under their care. Professor Morgan and the pathology department of Westminister Hospital for their help. Mr B. Sterry Ashby for his help and encouragement in writing this paper.

\section{References}

Ballanger, R. (1963) Gastric metastasis of a testicular carcinoma operated on twelve years earlier. Journa d'urologie et néphrologie, Paris, 69, 531.

Campbell, H.E. (1942) Incidence of malignant growth of undescended testicle. Archives of Surgery, Chicago, 44, 360.

Duomi, M. (1962) A malignant testicular tumour wit unusual metastases. British Journal of Clinical Practice, 21, 195.

Fleming, P.R. \& HARRISON, W.J. (1965) Intracardiac metastasis from a testicular tumour. British Heart Journal, 27, 465.

Johnson, W.A. \& Strauss, F.H. (1952) Intussusception of the small intestine produced by metastatic carcinoma. Surgery, 32, 991.

Prossor, T.M. (1964) Tumours of the testis. Journal of the Royal College of Surgeons of Edinburgh, 9, 85.

Pugh (1966) In: Report of the Testicular Tumour Panel.

Rivadeneyra, J. (1972) Metastasis a glandulas endocrinas. Ginecologia y obstetricia de Mexico, 31, 139.

SAlikA, N.S. (1966) Choriocarcinoma in a male patient presenting as gastro-intestinal haemorrhage. American Journal of Surgery, 112, 764.

Stephen, R.A. (1958) Malignant testicular tumour. Annals of the Royal College of Surgeons of England, 23, 71.

Whittle, R.J.M. (1958) Tumours of the testicle. British Journal of Radiology, 30, 7. 